\title{
Unilateral left lung agenesis with crossed-ectopic right lower lobe combined tricuspid atresia diagnosed by ECG gated computed tomography
}

\author{
Li-Lan Chiang, MD, ${ }^{\mathrm{a}}$ Shuenn-Nan Chiu, MD, ${ }^{\mathrm{a}}$ Shu-Chien Huang, MD, ${ }^{\mathrm{b}}$ and Shy-Jye Chen, MD, ${ }^{\mathrm{c}}$ Taipei, \\ Taiwan
}

Video clip is available online.

Lung agenesis, a rare congenital anomaly, is sometimes associated with multiple congenital anomalies. ${ }^{1}$ Young infants with this condition may face a catastrophic clinical course. We report an unusual case of lung agenesis with complex cardiac anomalies and crossed ectopic lung complicating diagnosis in a 6-month-old child.

\section{CLINICAL SUMMARY}

A boy was born uneventfully to a healthy mother at a gestational age of 37 weeks. Low birth weight $(1700 \mathrm{~g})$ and multiple congenital anomalies were found at birth, including large anterior fontanel and syndactyly over the second and third toes. Because tachypnea and heart murmur were heard 3 days after birth, serial workup was arranged. Chest radiography showed left lung haziness (Figure 1), and echocardiography showed tricuspid atresia, small ventricular septal defect, atrial septal defect, large patent ductus arteriosus, and suspected left pulmonary artery and pulmonary vein agenesis (Figure 2, $A$ and $B)$. Because of the suspected left lung agenesis, electrocardiographically gated chest computed tomography and 3-dimensional reconstruction were performed (Figure 2, $C$ and $D$, and Video 1). Crossed ectopic right lower lobe in the left hemithorax was found incidentally, in addition to left lung agenesis and tricuspid atresia. The arteries and veins supplying not only this lobe but also the bronchus of this lobe were from the right lung. The patient's respiratory distress and heart failure symptoms improved after anticongestive medication, and he was then discharged at 2 weeks old.

From Departments of Pediatrics, ${ }^{\mathrm{a}}$ Surgery, ${ }^{\mathrm{b}}$ and Medical Imaging, ${ }^{\mathrm{c}}$ National Taiwan University Hospital and National Taiwan University College of Medicine, Taipei, Taiwan.

Disclosures: None.

Received for publication Feb 17, 2009; accepted for publication March 7, 2009; available ahead of print June 18, 2009

Address for reprints: Shy-Jye Chen, MD, Department of Medical Imaging, National Taiwan University Hospital, 7 Chung-Shan S Rd, Taipei 100, Taiwan (E-mail: michael@ntuh.gov.tw).

J Thorac Cardiovasc Surg 2010;139:e110-1

$0022-5223 / \$ 36.00$

Copyright (c) 2010 by The American Association for Thoracic Surgery doi:10.1016/j.jtcvs.2009.03.052

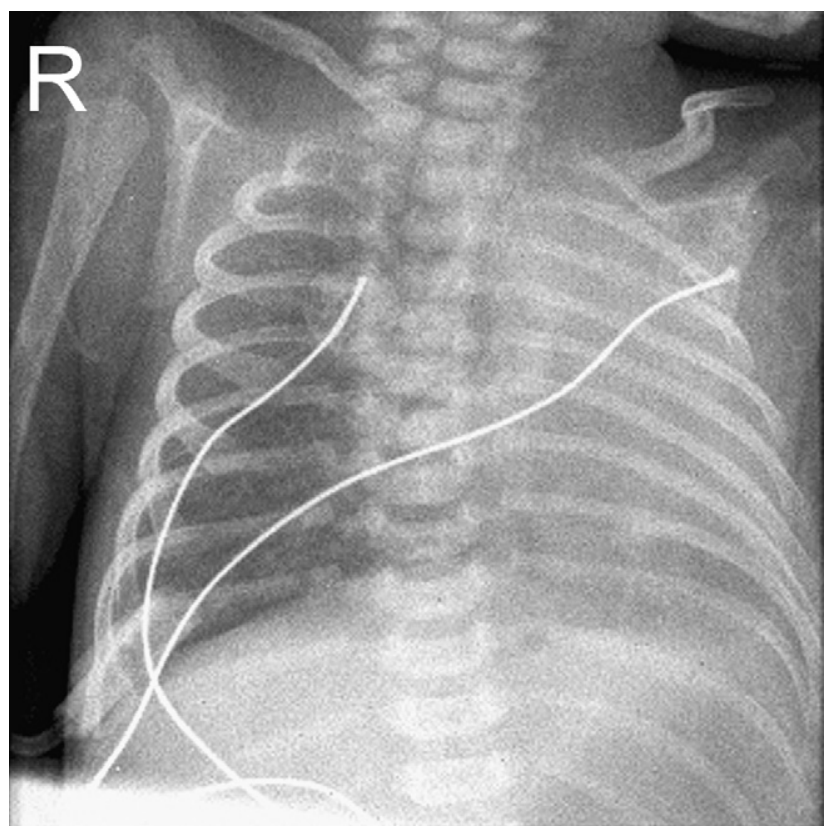

FIGURE 1. Chest radiograph showing opacified left upper and lower lung fields.

When the boy was 5 months old, mean pulmonary artery pressure was measured as $10 \mathrm{~mm} \mathrm{Hg}$ by cardiac catheterization. We then performed a staged operation including bidirectional Glenn shunt, atrial septal defect enlargement, and patent ductus arteriosus ligation for his tricuspid atresia. The postoperative course was uneventful, and the patient was discharged 10 days after the operation and followed up at our cardiology clinics. Total cavopulmonary circulation will be arranged in the future.

\section{DISCUSSION}

Lung agenesis is a rare congenital anomaly that may be associated with multiple congenital anomalies. ${ }^{1}$ Catastrophic clinical course may complicate the young infant stage. The diagnosis may be suspected on chest radiography; in rare cases, however, it may be associated with cross ectopic lung, which may cause misinterpretation of chest radiography. ${ }^{2}$ Chest computed tomography is therefore necessary for definitive diagnosis. For congenital heart disease, echocardiography is the most useful diagnostic tool, with good resolution and sensitivity. In many situations, 

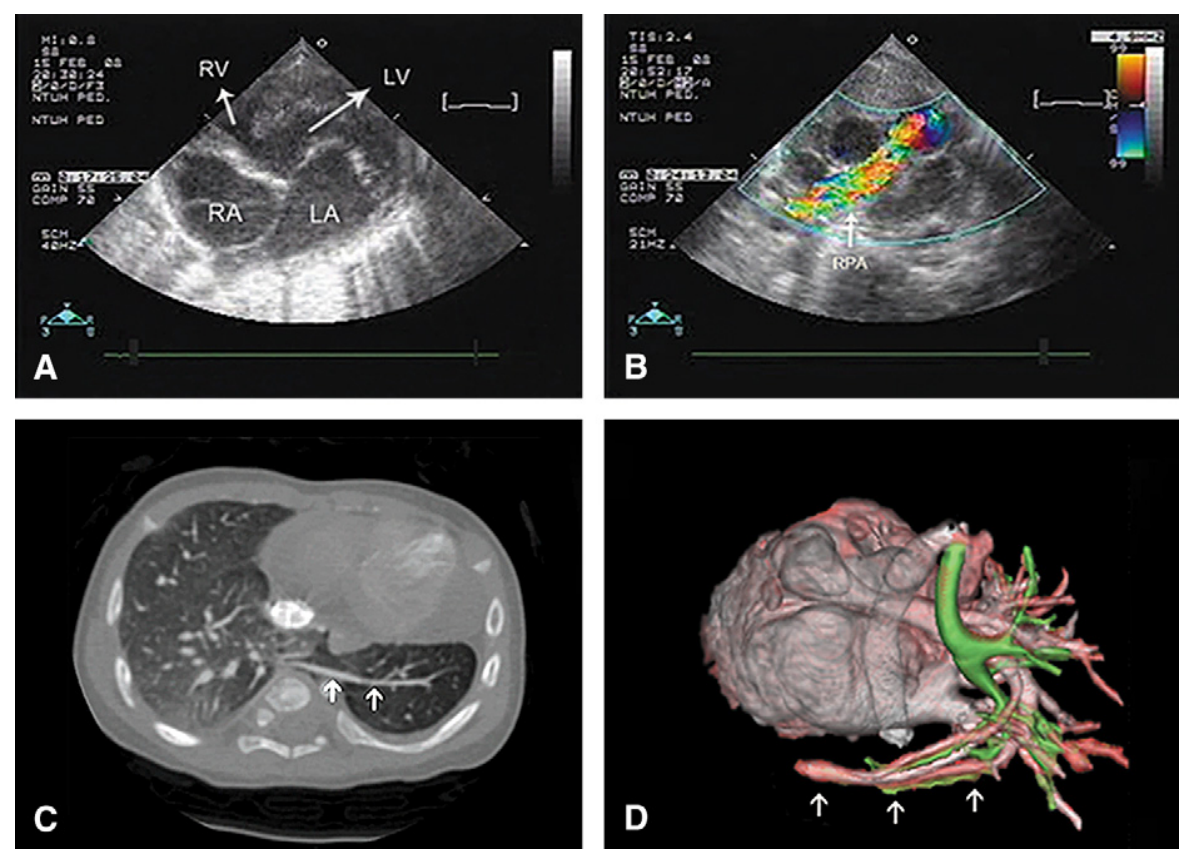

FIGURE 2. A, Echocardiogram showing tricuspid atresia with hypoplastic right ventricle on 4-chamber view. B, Parasternal short-axis echocardiogram showing left pulmonary artery atresia with pulmonary flow all directed into right pulmonary artery. C, Transverse cardiac computed tomography revealing connections of vessels and lung parenchyma of left lower thorax to right lower thorax (arrows). D, Three-dimensional volume rendering images viewed from dorsal cephalic aspect showing origin of pulmonary arteries, veins, and airways (green) of left lower thorax from right ones (arrows).

however, especially in the setting of complex congenital heart disease, electrocardiographically gated computed tomography is more useful not only for heart anatomy delineation but for provision of information about the relationship between the heart and adjacent organs, such as lung and trachea.

This patient had rare combination of lung agenesis and complex congenital heart disease. Because of tricuspid atresia and severe right ventricular hypoplasia, a Fontan-type operation was needed. There have been some reports of single-ventricle circulation operation in patients with atresia of a single pulmonary artery; however, reports are rare regarding patients with lung agenesis. ${ }^{3}$ We performed a bidirectional Glenn shunt operation smoothly without prolonged ventilation or hospital course. Operations to establish single-ventricle circulation physiology thus may be feasible for patients with lung agenesis, but longer follow-up is necessary.

\section{References}

1. Gabarre JA, Galindo Izquierdo A, Rasero Ponferrada M, Orbea Gallardo C, Puente Agueda JM, de la Fuente Pérez P. Isolated unilateral pulmonary agenesis: early prenatal diagnosis and long-term follow-up. $J$ Ultrasound Med. 2005;24:865-8.

2. Chen SJ, Li YW, Wu MH, Wang JK, Hsu JC, Lue HC. Crossed ectopic left lung with fusion to the right lung: a variant of horseshoe lung? Am J Roentgenol. 1997; 168:1347-8.

3. Jacobs ML, Schneider DJ, Pourmoghadam KK, Pizarro C, Norwood WI. Total cavopulmonary connection to one lung. Semin Thorac Cardiovasc Surg Pediatr Card Surg Аппи. 2004;7:72-9. 